Andrés Garcés

Ubicación

2 norte \#195 esquina 5

poniente, Viña del Mar

Colaboradores

Isab el Becker, arquitectura;

aime Reyes, diseño de mobiliario

Manuel Sanfuentes, diseño gráfico.

Cálculo estructural

Ernesto Domínguez

Construcción

Arco Ltda.

Materialidad

hormigón a la vista, mad era sólida

de ulmo, piedra pizarra

Superficie terreno

$317 \mathrm{~m}^{2}$

Superficie proyectada

$540 \mathrm{~m}^{2}$

Año proyecto

octubre de 1999

Año construcción

diciembre del 2000

\title{
Bar Restaurant Barlovento
}

La forma de este edificio nace a partir de un poliedro regular en su exterior, macizo y hermético, que contiene en su interior otro poliedro asimétrico vacío y de doble altura. En sus vértices, cuatro pilares hexagonales rematan en lucarnas que ordenan este espacio sosteniendo un cielo único para todo el edificio.

En el primer piso está el acceso principal que conduce directamente a la barra, centro del restaurant y adonde convergen todos los niveles interiores; ésta irrumpe desde una esquina en una prolongación de la cocina que queda a la vista del público y configurando una unidad de funcionamiento junto a la barra.

El segundo piso está concebido como un gran balcón que rodea parte del vacío central, extendiéndose en los lados poniente y norte. El muro poniente tiene unas pequeñas ventanas ordenadas por una secuencia numérica que dibujan el muro sin que en éste corte el plano completo. Sobre los $6.50 \mathrm{~m}$ está la terraza del tamaño de todo el edificio, las cuatro lucarnas son ahora cuatro grandes mesas que ordenan y dividen este espacio, quedando una parte central cubierta la que conforma una dirección diagonal al total de la planta como a todo el volumen del edificio.

Andrés Garcés

Arquitecto, Universidad Católica de Valparaíso, 1994; desde 1995 es miembro de la Ciudad Abierta de Amereida. Entre 1994 y 1998 trabaja con Cruz \& Browne arquitectos, a partir de 1959 se independiza. Desde Valpríso A prodir añog añ y de cursos superiores en la UCV.

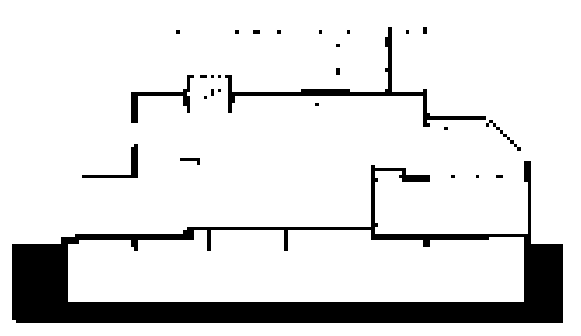

Corte AA'
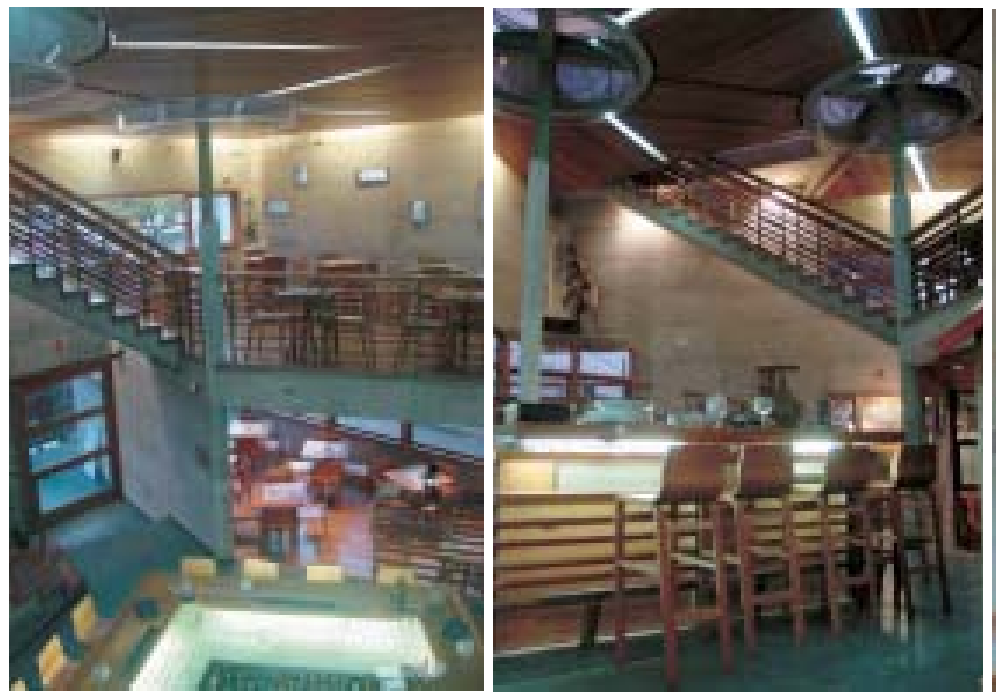
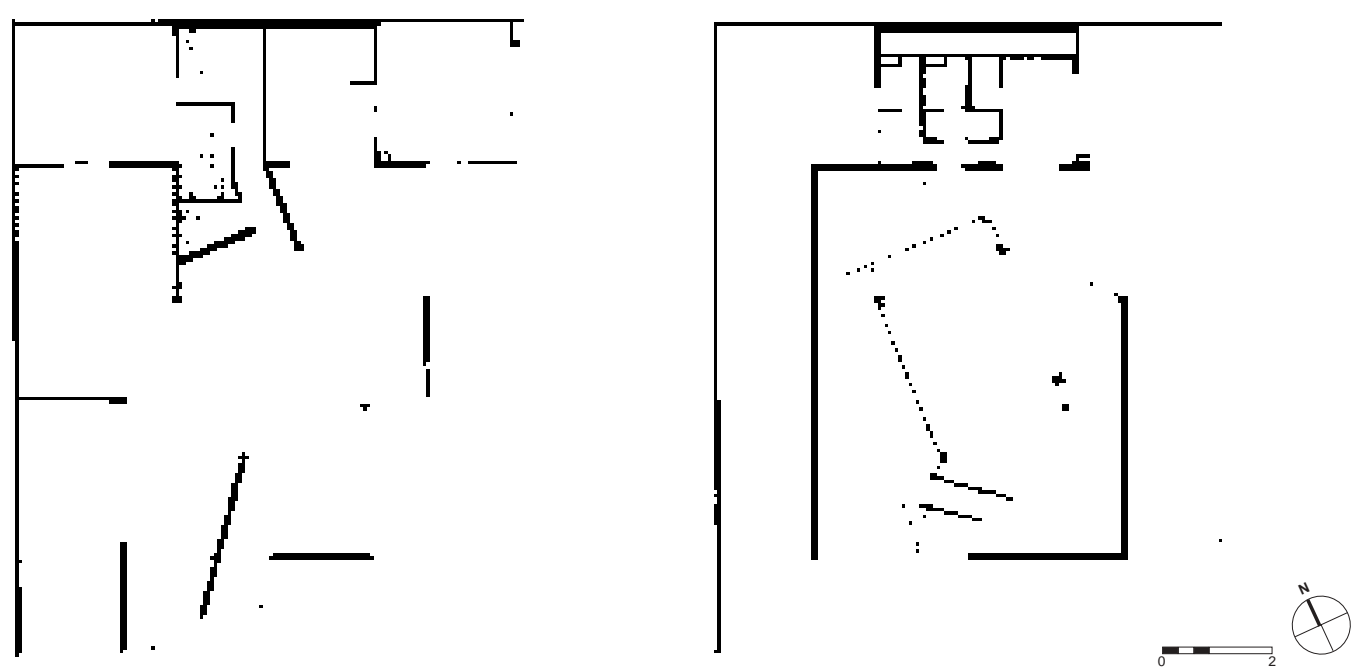

Planta segundo piso
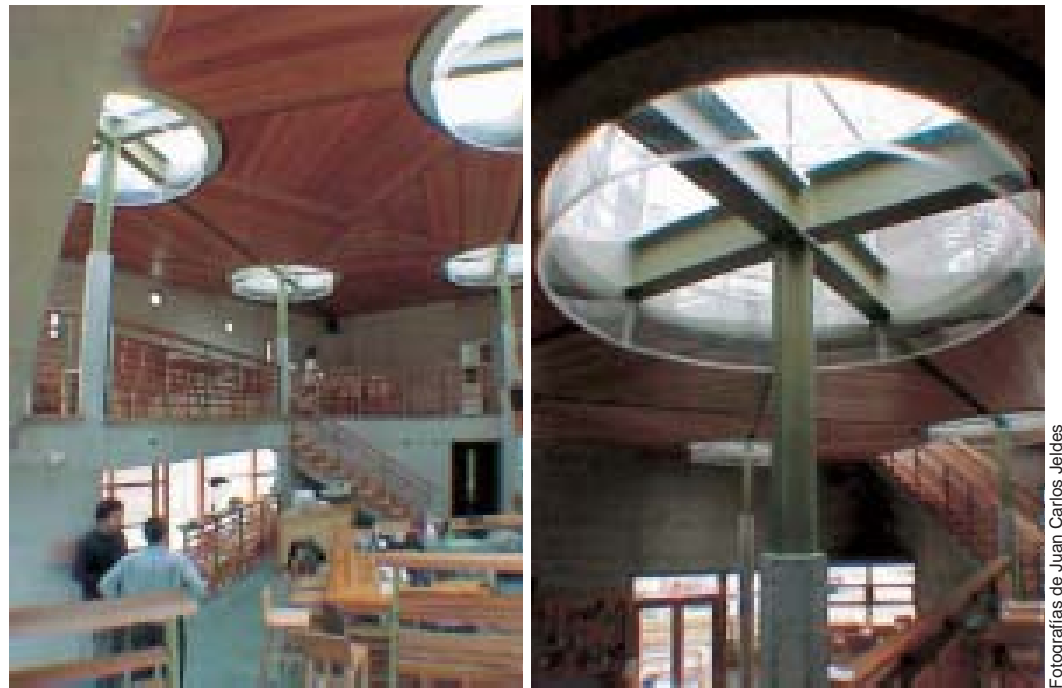